\title{
Rehabilitation targeted late adverse effects after radiotherapy for cervical cancer - Different gains in different settings
}

\author{
Karin B. Dieperink ${ }^{* 1,2}$, Lene Sigaard ${ }^{3}$, Helle Mona Larsen ${ }^{1}$, Tina Broby Mikkelsen ${ }^{2}$ \\ ${ }^{1}$ Department of Oncology, Academy of Geriatric Cancer Research (AgeCare), Odense University Hospital, Denmark \\ ${ }^{2}$ Danish Knowledge Centre for Rehabilitation and Palliative Care (REHPA), Denmark \\ ${ }^{3}$ Department of Hematology, Herlev Hospital, Herlev, Denmark
}

Received: September 10, 2017

DOI: $10.5430 /$ cns.v6n2p9
Accepted: November 26, 2017 Online Published: December 8, 2017

URL: https://doi.org/10.5430/cns.v6n2p9

\begin{abstract}
Many cervical cancer survivors experience late adverse effects, and rehabilitation may alleviate symptoms. This study describes participants' experiences with late adverse effects in daily living and with experiences of perceived rehabilitation in hospital, municipal, and a residential setting. Twenty-one cervical cancer survivors aged 40-72 years, curatively treated with concomitant radio-chemotherapy, with moderate/severe incontinence and sexual problems, participated in a 5-day residential rehabilitation intervention. Three focus group interviews were conducted and analyzed. Late adverse effects like incontinence, sexual problems, tinnitus and pain severely restricted everyday life. The participants described rehabilitation in hospital settings as fragmented, but several of the participants benefitted from the physical rehabilitation in municipal settings; however, no participants were offered sexual rehabilitation. In the residential setting, they gained a sense of connectedness and confidence in association with peers. More time to reflect and the anonymity gave opportunity to work with sensitive issues e.g. sexuality. Increased knowledge about late adverse effects and tools to alleviate these made the participants prepared to regain command of their lives. In conclusion, incontinence and tinnitus had especially impact on social life and every day activities. The participants benefitted especially from rehabilitation in two settings (municipal and residential). Intensively psychosocial interventions allowed participants to work with underlying problems. Women with sexual and/or incontinence problems favored the residential rehabilitation due to anonymity.
\end{abstract}

Key Words: Cervical cancer, Late adverse effects, Rehabilitation, Settings, Residential, Focus groups

\section{INTRODUCTION}

Worldwide about 500,000 women are diagnosed with cervical cancer annually. ${ }^{[1]}$ In 2014 , the 5-year survival rate in Denmark was $68 \%,{ }^{[2]}$ and almost 9,000 Danish women live with the disease. ${ }^{[3]}$ It is known from questionnaires that common physical problems after treatment for cervical cancer are anorectal dysfunction, urinary symptoms, sexual dysfunction, and lymphedema. Quality of life (QoL) may be impaired even 15 years after treatment. Radiotherapy is often used with curative intent, but radiotherapy is associated with reduced QoL. ${ }^{[4,5]}$ Cervical cancer survivors had clinically significant more problems with menopause, body image and sexual issues than the general population measured 5 years since treatment in a Korean population. ${ }^{[6]}$ A Dutch longitudinal cohort study, one and two years after treatment,

\footnotetext{
*Correspondence: Karin B. Dieperink; Email: karin.dieperink@rsyd.dk; Address: Odense University Hospital, Southern Boulevard 29, DK-5000
} Odense C, Denmark. 
found that radiotherapy had a negative effect on diarrhea, and lymphedema. ${ }^{[7]}$ The above mentioned late adverse effects are seen in different time periods since treatment, and also age seems to be an influencing factor. Younger women $<45$ years are more influenced by late adverse effects from their bowels, and have more problems with body image and sexual issues than older women. ${ }^{[8]}$

Although knowledge is emerging from questionnaires about the extent of pre-defined late adverse effects after cervical cancer, more seldom late adverse effects, and the influence on everyday life and knowledge of how best to rehabilitate these women is limited. Short-term rehabilitation needs have been reported in a Danish population with radiated cervical cancer patients $(n=23)$. A qualitative analysis indicated that radiotherapy and marital status as single severely impacted coping, and women younger than 55 years more often request help to deal with sexual and psychological complications. ${ }^{[9]}$

In Denmark cancer rehabilitation is offered in different settings: hospitals or municipalities, and organized as either inpatients or outpatients. To our knowledge, no intervention studies have investigated how to rehabilitate women after radiotherapy for cervical cancer, and in which setting they may benefit the most. This study initiated and executed a 5-day residential intervention at Rehabilitation Centre Dallund (RcDallund) with focus on urinary, bowel, sexual, and body image problems in patients with late adverse effects after radiotherapy for cervical cancer.

\section{Purpose}

The study aimed to:

- Investigate the participants' experiences of late adverse effects and impact on everyday life after treatment for cervical cancer.

- Investigate the participants' experiences of rehabilitation in different settings, before and during a multidisciplinary residential rehabilitation intervention.

\section{MeTHODS}

\subsection{Design and participants}

A qualitative approach using focus groups explored cervical cancer patients. The patients had all participated in a former survey regarding late adverse effects. ${ }^{[10]}$ In the former survey, all patients treated at Odense University Hospital from 2010 to June 2013 with curative intent and with no relapse were send the health-related QoL questionnaire EORTC QLQ$30^{[11]}$ and the disease specific questionnaire EORTC QLQ CX24. ${ }^{[12]}$

Inclusion criteria: Patients who reported moderate to severe problems regarding urinary, bowel, sexual, and body image assessed by EORTC QLQ CX24 were included in the present qualitative study. Exclusion criteria: patients not speaking Danish and those not able to participate in rehabilitation at RcDallund.

We included the participants in 1 of 3 focus group interviews during their stay at RcDallund in April or October 2014.

\subsection{Cervical cancer treatment}

The women were all treated according to guidelines by the Danish Gynecological Cancer Group (DGCG) ${ }^{[13]}$ and the Nordic Society for Gynecological Oncology (NSGO). Patients received concomitant radio-chemotherapy. The radiotherapy was given as external radiation in combination with brachytherapy. Tumor received a total of $80 \mathrm{GY}$, pathological lymph nodes $64 \mathrm{GY}$ and elective lymph nodes 50 or $45 \mathrm{GY}$. During radiotherapy Cisplatin was given weekly $40 \mathrm{mg} / \mathrm{m}^{2}$ for 5 or 6 cycles.

\section{Compliance with Ethical Standards}

The study was completed according to the Helsinki II declaration. Verbal and written informed consent was obtained. Participants were informed about the purpose of the study and that they would be anonymous. The participants could withdraw from the study at any time. The study was indexed in the Danish Data Protection agency with no. 2008-58-0035. Data was stored safely in a Sharepoint site.

\subsection{Rehabilitation}

From 2001 until closure in 2015, RcDallund was the only center in Denmark offering rehabilitation to cancer survivors in a residential setting. Rehabilitation was executed and coordinated by interdisciplinary professionals; social worker, physiotherapists, nurses, dietician sexologist, psychologist, and massage therapists.

The core of this particularly 5-day-program (see Table 1) was developed to focus on the special needs of cervical cancer survivors and consisted of information and knowledge sharing about physical late adverse effects, nutrition important to rebuild health after cancer, group-based sexual counseling, and debates about the strong connection with intimacy. Also, physical activities including pelvic floor exercises were executed as individual or group-based training, depending on the participants needs. Furthermore, psychological reactions e.g. fear of recurrence, and social issues were addressed. Presentations and discussions about the challenges of getting back to work and sessions with massage therapy and individual therapeutic talks targeting individual problems were offered. Finally, each participant described an individual activity plan to work with in the future. The cancer rehabilitation in this special residential context has been described in detail previously. ${ }^{[14]}$ Notably, social processes could continue during the 
entire week because the participants shared cultural events ticipants/professionals shared meals together. ${ }^{[14]}$ together, had breaks together between sessions, and the par-

Table 1. Timetable of a residential rehabilitation course for Danish women treated for cervical cancer. The primary focus was late adverse effects after cancer treatment and methods to counteract these.

\begin{tabular}{|c|c|c|c|c|c|}
\hline Time & Monday & Tuesday & Wednesday & Thursday & Friday \\
\hline $7: 00$ & & Physical activity & Physical activity & Physical activity & Physical activity \\
\hline $7: 30$ & & Buffet breakfast & Buffet breakfast & Buffet breakfast & Buffet breakfast \\
\hline \multirow[t]{4}{*}{$8: 15$} & & Morning gathering & Morning gathering & Morning gathering & Morning gathering \\
\hline & $\begin{array}{l}\text { Arrival and } \\
\text { registration }\end{array}$ & & $\begin{array}{l}\text { Cancer and psychological } \\
\text { reactions } \\
\text { (psychologist) }\end{array}$ & $\begin{array}{l}\text { Individual } \\
\text { conversations } \\
\text { depending on needs }\end{array}$ & $\begin{array}{l}\text { Motivation, changes, and } \\
\text { action plans } \\
\text { (course leader) OR } \\
\text { Focus group interviews } \\
\text { (researcher) }\end{array}$ \\
\hline & $\begin{array}{l}\text { Welcome and } \\
\text { presentation of } \\
\text { program for week } \\
\text { (course leader) }\end{array}$ & $\begin{array}{l}\text { Cervical cancer, treatment } \\
\text { and late adverse effects } \\
\text { (physician) OR } \\
\text { Cancer and sexuality } \\
\text { (sexologist) } \\
\text { Pelvic floor exercises } \\
\text { (physiotherapist) }\end{array}$ & $\begin{array}{l}\text { Pelvic floor exercises } \\
\text { (physiotherapist) OR } \\
\text { Visualization } \\
\text { (nurse) }\end{array}$ & $\begin{array}{l}\text { Massage Therapy } \\
\text { (massage therapist) }\end{array}$ & $\begin{array}{l}\text { Work with action plans } \\
\text { (course leader) }\end{array}$ \\
\hline & $\begin{array}{l}\text { Walk around the lake } \\
\text { (Prepared questions) }\end{array}$ & & & & \\
\hline \multirow[t]{3}{*}{$12: 30$} & Buffet lunch & Buffet lunch & Buffet lunch & Buffet lunch & Buffet lunch \\
\hline & $\begin{array}{l}\text { Round of } \\
\text { introductions of } \\
\text { participants }\end{array}$ & $\begin{array}{l}\text { Cervical cancer, treatment } \\
\text { and late effects } \\
\text { (physician) OR } \\
\text { Cancer and sexuality }{ }^{*} \\
\text { (sexologist) }\end{array}$ & $\begin{array}{l}\text { Cancer and psychological } \\
\text { reactions } \\
\text { (psychologist) OR } \\
\text { Visualisation } \\
\text { (nurse) }\end{array}$ & $\begin{array}{l}\text { Back to work } \\
\text { (social worker) }\end{array}$ & $\begin{array}{l}\text { Discussion of action plans } \\
\text { in small groups }\end{array}$ \\
\hline & $\begin{array}{l}\text { Cancer and diet } \\
\text { (dietician) }\end{array}$ & & & & $\begin{array}{l}\text { Closure and goodbye } \\
\text { (course leader) }\end{array}$ \\
\hline \multirow[t]{2}{*}{$18: 00$} & Dinner & Dinner & Dinner & Dinner & \\
\hline & Concert & Art workshop activities & Patients association & & \\
\hline
\end{tabular}

Note. ${ }^{*}$ Participants were divided into two groups and attended a session on late adverse effects or sexuality before lunch and the opposite after lunch

\subsection{Focus group interviews}

Focus groups were conducted due to the advantage of group dynamics which is to stimulate discussion, to gain insights, and also to generate ideas in order to pursue a topic in greater depth. ${ }^{[15-17]}$ An experienced research nurse and two assistants facilitated the focus groups and used a semi-structured interview guide. All interviews were tape-recorded and transcribed verbatim. NVivo was used to code and manage the qualitative data, and COREQ was used as a guideline for reporting the study. ${ }^{[18]}$

All 3 focus groups were analyzed with meaning condensation based on inspiration from Giorgi's phenomenological approach. ${ }^{[19]}$ This was a descriptive procedure containing five steps: (1) We obtained a general understanding by reading the transcript and derived a global sense of the whole text. The reading was conducted with a maximum of openness, and not with the specific purpose of this study in mind. A summary of the focus groups was noted. (2) We divided the text into meaning units, as they were expressed with the participants' own words. Irrelevant text not related to the specific purpose of this study was deleted. The social interaction, both the body and verbal language, was an important part of the focus groups, and was therefore noticed by one of the research assistants. ${ }^{[20]}$ (3) Each meaning unit, as expressed by the participants, was examined and transformed to the researcher's language. Central aspects of the phenomenon were enhanced by adding memos to each meaning unit. (4) We investigated the meaning units based on the specific research questions. (5) Finally, we revealed the essential structure, and synthesized the converted meaning units into descriptive statements.

\subsection{Research team and reflexivity}

The researchers were experienced in cancer nursing and in rehabilitation research. Our epistemological assumption was that the participants' experiences regarding late adverse effects and rehabilitation were individual experiences but altered by the women. Therefore, the interaction between the participants was carefully observed. To avoid bias two of 
the researchers KD and LS conducted the analysis, and the results were validated by the whole research team.

In the next section, quotes illustrating the analytical points represent the themes derived from the text.

\section{RESULTS}

\subsection{Participants}

Eighty-five cervical cancer patients treated from 2010-2013 at Department of Oncology, Odense University Hospital, Denmark filled in EORTC QLQ CX24. Of those 56/85 $(66 \%)$ had moderate to severe problems within bowel, urinary, body image or sexual domains. ${ }^{[10]}$ These women, most affected by late adverse effects, were invited to a 5-day residential intervention at RcDallund, and 21/56 women (38\%) accepted. The self-reported symptoms of these 21 women are described in Table 2. The 35 woman who rejected the invitation had various explanations, e.g. the time didn't fit because of work or other obligations, or they did not need it. The mean age of the twenty-one participating women was 53 years (range 40-72 years). Women who agreed to participate were significantly younger than the women who refused (53 and 59 years, respectively, $p<.02$ ). Furthermore, $38 \%$ of the non-participating women reported moderate to severe diarrhea, whereas only $19 \%$ of the participants did. More participants were married or living with a partner $(76 \%)$ than those who refused (53\%), and more participants had children living at home (67\%) than those who did not participate (29\%). The majority had received tertiary education and was employed (see Table 3). Four of the participants had been to RcDallund before in weeks with mixed cancer diagnoses.

\subsection{Late adverse effects}

In the following section, the participants' experiences with late adverse effects after treatment are described.

The quotations are selected to reproduce typical and illustrative responses from all three focus groups. The experiences of late adverse effects consisted of 3 themes: Physical problems; Psychological problems; and Social problems.

\subsection{Theme: Physical problems}

\subsubsection{Incontinence}

Most participants had experienced problems with incontinence of urine and/or feces, numerous urinary tract infections, and problems with diarrhea and constipation. Common to the incontinence problems was that the participants developed different coping strategies to remedy the problems in daily life. Bladder and bowel problems could lead to periods of isolation and had a negative impact on social interactions.

Table 2. Danish women with cervical cancer with moderate to severe of the following symptoms $(\mathrm{n}=21)$

\begin{tabular}{ll}
\hline Question from EORTC QLQ CX24 & $\begin{array}{l}\text { Moderate to severe problems } \\
\text { Number (\%) }\end{array}$ \\
\hline Have you had difficulty in controlling your bowels? & $2(10)$ \\
Did you pass water/urine frequently? & $12(57)$ \\
Have you had leaking of urine? & $6(29)$ \\
Have you had difficulty emptying your bladder? & $4(19)$ \\
Have you had pain in your lower back? & $6(29)$ \\
Have you had hot flushes and/or sweats? & $11(52)$ \\
Have you felt physically less attractive as a result of your disease or treatment? & $6(29)$ \\
Have you felt less feminine as a result of your disease or treatment? & $6(29)$ \\
Have you felt dissatisfied with your body? & $6(29)$ \\
Was sexual activity enjoyable for you? & $8(67)$ \\
\hline
\end{tabular}

Note. ${ }^{*}$ For those who have been sexually active during the past 4 weeks, 12 women answered this question and 8 had moderate to severe problems

"In order not to risk anything, I have clean panties and diapers with me everywhere."

\subsubsection{Pain}

Several participants had musculoskeletal pain for which they had no explanation. These problems caused limitations in work and family life. The participants could understand that some pain and discomfort could arise in the area where the cancer had been located, although exacerbation was a reminder that something could be wrong. To share the pain with spouses gave an immediate sense of security, but in the long run it could also be a stain on the relationship.

"I tell my husband when it hurts just so he knows what to be aware of. But I do understand that he gets tired of hearing me moan all the time."

\subsubsection{Tinnitus}

Most participants had tinnitus to various extents. Tinnitus was experienced as a severe nuisance in everyday life that 
was enhanced by ambient noise and had a restrictive effect of social life. Several of the participants reported that tinnitus was not recognized as an important late adverse effect by the health care professionals, contrary to the participants' perceptions.

"If we are many people gathered the talk flows. The day after it howls insanely in my ears."

Table 3. Characteristics of 21 Danish women treated for cervical cancer participating in residential rehabilitation

\begin{tabular}{|c|c|c|c|c|}
\hline $\begin{array}{l}\text { Participant } \\
\text { no. }\end{array}$ & Age & Education ${ }^{*}$ & $\begin{array}{l}\text { Socio-economic } \\
\text { group }\end{array}$ & $\begin{array}{l}\text { Civil } \\
\text { status }\end{array}$ \\
\hline \multicolumn{5}{|c|}{ Focus Group 1} \\
\hline FG1-1 & 72 & Primary & Retired & Single \\
\hline FG1-2 & 46 & Tertiary & Employed & Married \\
\hline FG1-3 & 53 & Tertiary & Un-employed & Married \\
\hline FG1-4 & 57 & Tertiary & Employed & Married \\
\hline FG1-5 & 68 & Primary & Employed & Cohabitant \\
\hline FG1-6 & 50 & Primary & Employed & Married \\
\hline FG1-7 & 40 & Tertiary & Employed & Married \\
\hline FG1-8 & 49 & Tertiary & Retired & Single \\
\hline \multicolumn{5}{|c|}{ Focus Group 2} \\
\hline FG2-1 & 50 & Youth & Student & Cohabitant \\
\hline FG2-2 & 58 & Primary & Un-employed & Cohabitant \\
\hline FG2-3 & 42 & Tertiary & Employed & Single \\
\hline FG2-4 & 39 & Tertiary & Employed & Married \\
\hline FG2-5 & 44 & Primary & Employed & Married \\
\hline FG2-6 & 40 & Tertiary & Un-employed & Single \\
\hline FG2-7 & 50 & Tertiary & Employed & Married \\
\hline \multicolumn{5}{|c|}{ Focus Group 3} \\
\hline FG3-1 & 52 & Tertiary & Employed & Married \\
\hline FG3-2 & 71 & Tertiary & Retired & Married \\
\hline FG3-3 & 50 & Tertiary & Employed & Single \\
\hline FG3-4 & 52 & Tertiary & Employed & Single \\
\hline FG3-5 & 57 & Tertiary & Employed & Married \\
\hline FG3-6 & 69 & Tertiary & Retired & Married \\
\hline
\end{tabular}

\subsubsection{Sexual problems}

Physical complaints like pain and bleeding were limitations for sexual acts and for feelings of desire and satisfaction. Some participants found their relationship improved especially if they had managed to focus on other sides of intimacy. Other participants found the relationship weakened, because of changes in previous sexual habits.

"Nor is it (sexual intercourse) a pleasure for my husband."

\subsection{Theme: Psychological problems}

\subsubsection{Cognitive problems}

Many participants experienced cognitive problems like memory and concentration difficulties. The symptoms were experienced as stressful not only for the women but also for family, colleagues and friends. Fatigue magnified these symptoms.

"Although I only have to buy two things, I have to write it down.”

\subsubsection{Emotional problems}

Both disease and treatment caused emotional challenges. Some women felt that the disease would forever be a threat and they had lost control. Some participants were thankful and could transform this in a positive way in their new lives.

"I am so happy to be alive and wake up each morning with gratitude."

\subsection{Theme: Social problems}

Both family and participants had experienced changes in social relationships. Some experienced an expectation from relatives to move on - disease should no longer be an issue. In other families, it was a major challenge to reduce the high degree of previous helpfulness.

"My family would like to take a little more care of me, but now I need to take care of myself."

Physical, psychological, and social problems involved everyday life in various ways. The late adverse effects could be inversely related, and one unsolved problem that was basically a physical problem could be transferred to either a psychological or a social problem or both, e.g. incontinence.

\subsection{Rehabilitation}

In this section the participants' experiences with rehabilitation in different settings are reported.

\subsubsection{Theme: Rehabilitation in a hospital setting}

In general, the word rehabilitation was not used during treatment. However, two of the participants were referred to a pressure chamber to relief sting and pain in the bladder caused by radiotherapy. In the hospital, most of the participants had received information about pelvic floor exercises, but the information could be too theoretical, sometimes involving only a pamphlet, and the exercises therefore difficult to do without supervision. Furthermore, most women had received information about using a vaginal dilator during their stay in the hospital, but they described the information as coincidental. For many, the use of vaginal dilator felt a bit humiliating, thus restricting usage.

\subsubsection{Theme: Rehabilitation in municipal settings}

Before RcDallund, several participants had been offered rehabilitation in their own municipality. In most municipalities, physical rehabilitation involved exercises twice a week in mixed gender groups and/or groups with different cancer diagnoses, especially breast cancer or in groups with different chronic diagnoses, e.g. heart diseases or diabetes.

"I have been to rehabilitation in my city with people with different diagnosis and gender. There was not the same close- 
ness as in this forum (RcDallund), not at all. It was goodreally good for me at that time. But this (RcDallund) is an entirely different experience."

Although the participants in general benefitted from the municipal rehabilitation, they felt it forced them to relate to other people's suffering and different problems.

Participants were not always aware of the existence of the municipal rehabilitation programs and what they could achieve by participating. Furthermore, rehabilitation programs did not always fit in with family and work. Three of the participants had been to a psychologist, and some sought counseling by the Danish Cancer Society. Other participants contacted the patient association for women with gynecological cancer and felt it was a help during the treatment period. Especially the help from peer patients was emphasized.

"Sometimes I really need to talk with someone who understands... and not explain."

None of the women were offered sexual rehabilitation in the municipalities, although sexual problems were significant. In the municipal setting, the participants had some reservations regarding discussion of intimate issues, as one said:

"When I go to my municipal setting, I may meet my neighbor. That's fine but she doesn't need to know about my sex life."

Furthermore, the women underlined the importance of being ready to talk about intimate matters and that it demanded a certain amount of confidence in a trusted person.

\subsubsection{Theme: Rehabilitation in residential setting}

At RcDallund, the participants experienced a feeling of connectedness and confidence with women with the same disease and living with the same problems. This connectedness developed over the week. These women were able to exchange individual but similar stories which reduced their' feelings of being alone and being stigmatized. Some kind of normalization was achieved.

"I thought I was the only one with this disease. I'm not...."

The new knowledge about late adverse effects after cervical cancer, and the tools to alleviate the problems, gave the participants a sense of having control again. Some symptoms caused by late adverse effects were mixed with fear of recurrence of the cancer, and this caused unnecessary suffering. These shared narratives helped the women to mirror each other and also to cope with the late adverse effects.

"I did not know these things. . about late adverse effects. Now I know and things make sense."

The surroundings and time to reflect and the anonymity gave the opportunity to discuss difficult and intimate questions regarding everyday life.

"We are not suddenly interrupted here, and we don't have to go home and take care of our family."

Although the families were not invited to RcDallund, they were part of almost every conversation between the participants, and the family was generally described as very supportive. But at RcDallund, the participants met a deeper understanding from peers.

"Even though you have a good network - they will never quite understand what fear you have."

It was essential that the problems the women experienced in different time periods were targeted in the rehabilitation program and modified to meet the needs of each individual person. In general, the participants benefitted from the intensive course and were given hope to go further with their lives.

"We had lost the power and control over body and mind... but now we are ready to take it back."

The four previous RcDallund participants described the outcome of this stay as different because it was targeted more specifically to their needs regarding cervical cancer.

\section{Discussion}

This study explored the participants' experiences of moderate to severe late adverse effects after radiotherapy for cervical cancer and their experiences regarding rehabilitation executed in different settings. Obviously, late adverse effects like urine and bowel incontinence, pain, and tinnitus were intrusive on everyday life. But also sexual, cognitive, and emotional problems influenced the women's identity in their roles as mothers, wives, and colleagues.

Rehabilitation was not distinctly articulated in the hospital setting, but some participants had received interventions like pamphlets with pelvic floor exercises and information about dilatator use and pressure chambers. Most had experienced physical rehabilitation in the municipalities, and the participants benefitted from these physical interventions, but found them sporadic and not targeted to their specific needs related to cervical cancer. Furthermore, sexual rehabilitation had not been offered in the municipalities. The time to reflect in the residential setting and the anonymity of being away from their own community, gave the participants the opportunity to share difficult and intimate issues regarding incontinence and sexuality.

\subsection{Late adverse effects}

The participants were selected from a defined population, and had moderate/severe urinary, bowel, sexual, and body image problems assessed by EORTC QLQ CX-24. ${ }^{[10]}$ How- 
ever, in this qualitative study the participants also expressed severe problems with tinnitus, and this late adverse effect is not described in the validated surveys. Tinnitus is a common cisplatin-induced ototoxicity and a known adverse effect. ${ }^{[21]}$ All participants had a hearing test performed before treatment, but the participants did not feel that they had been properly informed how to deal with tinnitus, and it had a significant impact on everyday life. This may be a reminder for clinicians to follow-up on late adverse effects like tinnitus after treatment.

Before the intervention at RcDallund, some of the problems were not recognized by our participants as late adverse effects because they ascribed them to aging or at worst a relapse. By talking with peers and receiving qualified information, they realized that they had late adverse effects. This phenomenon is also found in prostate cancer survivors, ${ }^{[22]}$ and information about late adverse effects after cancer should be considered included in clinical practice as a standard for cancer survivors.

\subsection{Rehabilitation}

This study showed that patients who did not participate were older and had more diarrhea than the participating women. We do not know whether these factors caused the refusal, but this information could be important to consider when planning rehabilitation interventions, e.g. description of toilet access.

The participants mentioned that talk about sexuality and sexual rehabilitation should be carefully planned and take care of individual concerns. A cross-sectional study $(n=343)$ found that $51 \%$ of the women would appreciate information and help regarding sexuality but only $35 \%$ of them managed to initiate a conversation with a professional about sexuality. ${ }^{[23]}$ This could indicate that the health care professionals should be the active part and start the conversation, but, as shown in this study, with sense of propriety. The use of vaginal dilator was a big problem for most of our participants, in line with other reports. ${ }^{[2]}$ A Dutch group by Bakker et al found that information about the use of vaginal dilators should be provided by radiation oncologists before radiotherapy, and psychological and practical support calls for trained oncology nurses. ${ }^{[25]}$

\subsection{Trustworthiness}

Three focus groups were executed, which is suggested as a minimum by Krueger. ${ }^{[26]}$ Each focus group consisted of 6 to
8 participants, which was manageable for the moderator and allowed all participants to talk.

The social behaviour between the women was important to observe. ${ }^{[20]}$ However, the focus group participants seemed to be homogeneous and on the same wavelength, but we do not know whether this prevented a maximal variation in the themes. However, the maximal variation was restricted by the inclusion criteria, as all women had to have moderate/severe problems. Another drawback was that only $38 \%$ of the patients with moderate/severe problems accepted the invitation to RcDallund. Two researchers were employed at RcDallund at the time. Therefore, data analysis and interpretation were systematically looked over and discussed by the whole research team which also included one author LS with no preference for RcDallund. Another limitation of the study was that the interviews were conducted on the last day of the residential stay, perhaps influencing the participants' preference for the residential setting.

\section{Conclusions}

In conclusion, this study showed that physical and psychosocial late adverse effects after concomitant radiochemotherapy for cervical cancer are intrusive and have impact on everyday life in various ways. The participants benefitted from rehabilitation in different settings. However, rehabilitation in hospitals could be more articulated and visible e.g. include information about the risk of possible late adverse effects, and be incorporated in the follow-up. Physical rehabilitation in the municipalities was considered beneficial. The intense psychosocial intervention in a residential setting allowed the participants to work with underlying problems especially sexual ones. Rehabilitation must target the exact late adverse effects expressed by the individual cervical cancer survivor and her needs.

\section{ACKNOWLEDGements}

We especially wish to thank the women who participated in the study for their valuable contributions. This research is behalf of the Academy of Geriatric Cancer Research www . agecare . org.

\section{Conflicts of InTEREST Disclosure}

The authors report no conflict of interest. The authors alone are responsible for the content and writing of the paper. 


\section{REFERENCES}

[1] Ferlay J, Soerjomataram I, Dikshit R, et al. Cancer incidence and mortality worldwide: sources, methods and major patterns in GLOBOCAN 2012. International Journal of Cancer. 2015; 136(5): E359. PMid: 25220842. https://doi.org/10.1002/ijc. 29210

[2] Engholm G, Ferlay J, Christensen N, et al. NORDCAN: Cancer Incidence, Mortality, Prevalence and Survival in the Nordic Countries. 2016 Version 7.1. 2015 [cited 201617 August]. Available from: http://www.ancr.nu

[3] The Danish Health Data Authority. New incidences of cancer in Denmark. 2015.

[4] Ye S, Yang J, Cao D, et al. A systematic review of quality of life and sexual function of patients with cervical cancer after treatment. Int J Gynecol Cancer. 2014; 24(7): 1146-57. PMid: 25033255. https://doi.org/10.1097/IGC. 0000000000000207

[5] Le Borgne G, Mercier M, Woronoff AS, et al. Quality of life in long-term cervical cancer survivors: a population-based study. Gynecol Oncol. 2013; 129(1): 222-8. PMid: 23280088. https: //doi.org/10.1016/j.ygyno.2012.12.033

[6] Park SY, Bae DS, Nam JH, et al. Quality of life and sexual problems in disease-free survivors of cervical cancer compared with the general population. Cancer. 2007; 110(12): 2716-25. PMid: 17960806. https ://doi.org/10.1002/cncr. 23094

[7] Pieterse QD, Kenter GG, Maas CP, et al. Self-reported sexual, bowel and bladder function in cervical cancer patients following different treatment modalities: longitudinal prospective cohort study. Int J Gynecol Cancer. 2013; 23(9): 1717-25. PMid: 24172106. https://doi.org/10.1097/IGC.0b013e3182a80a65

[8] Bifulco G, De RN, Tornesello ML, et al. Quality of life, lifestyle behavior and employment experience: a comparison between young and midlife survivors of gynecology early stage cancers. Gynecol Oncol. 2012; 124(3): 444-51. PMid: 22119994. https://doi.or $\mathrm{g} / 10.1016 / \mathrm{j} \cdot$ ygyno.2011.11.033

[9] Jeppesen MM, Mogensen O, Dehn P, et al. Needs and priorities of women with endometrial and cervical cancer. J Psychosom Obstet Gynaecol. 2015; 36(3): 122-32. PMid: 26123123. https: //doi.org/10.3109/0167482X.2015.1059417

[10] Mikkelsen TB, Sorensen B, Dieperink KB. Prediction of rehabilitation needs after treatment of cervical cancer: what do late adverse effects tell us? Support Care Cancer. 2017; 25(3): 823-831. PMid: 27834003. https://doi .org/10.1007/s00520-016-3466-x

[11] Aaronson NK, Ahmedzai S, Bergman B, et al. The European Organization for Research and Treatment of Cancer QLQ-C30: a quality-of-life instrument for use in international clinical trials in oncology. J Natl Cancer Inst. 1993; 85(5): 365-76. PMid: 8433390. https://doi.org/10.1093/jnci/85.5.365

[12] Greimel ER, Kuljanic VK, Waldenstrom AC, et al. The European Organization for Research and Treatment of Cancer (EORTC) Quality-of-Life questionnaire cervical cancer module: EORTC
QLQ-CX24. Cancer. 2006; 107(8): 1812-22. PMid: 16977652. https ://doi.org/10.1002/cncr. 22217

[13] Danish gynaecological cancer group DGCG. Guidelines for visitation, diagnosis, treatment and control of cervical cancer. 2011.

[14] Tjornhoj-Thomsen T, Hansen HP. The ritualization of rehabilitation. Med Anthropol. 2013; 32(3): 266-85. PMid: 23557009 https://doi.org/10.1080/01459740.2011.637255

[15] Morgan DL. Focus groups as qualitative research. London: Sage Publications; 1997. https://doi.org/10.4135/9781412984287

[16] McLafferty I. Focus group interviews as a data collecting strategy. J. Adv. Nurs. 2004; 48(2): 187-194. PMid: 15369499. https: //doi.org/10.1111/j.1365-2648.2004.03186.x

[17] Freeman T. "Best Practice" in focus group research: making sense of different views. J Adv Nurs. 2006; 56(5): 491-497. PMid: 17078825. https://doi.org/10.1111/j.1365-2648.2006.04043.x

[18] Tong A, Sainsbury P, Craig J. Consolidated criteria for reporting qualitative research (COREQ): a 32-item checklist for interviews and focus groups. Int J Qual Health Care. 2007; 19(6): 349-57. PMid: 17872937. https : //doi.org/10.1093/intqhc/mzm042

[19] Giorgi A. The phenomenological movement and research in the human sciences. Nurs. Sci. Q. 2005; 18(1): 75-82. PMid: 15574702. https ://doi .org/10.1177/0894318404272112

[20] Halkier B. Focus groups as social enactments: integrating interaction and content in the analysis of focus group data. Qualitative Research. 2010; 10(1): 71-89. https ://doi.org/10.1177/146879410934 8683

[21] Travis LB, Fossa SD, Sesso HD, et al. Chemotherapy-induced peripheral neurotoxicity and ototoxicity: new paradigms for translational genomics. J Natl Cancer Inst. 2014; 106(5): 2504-2511. PMid: 24623533. https://doi.org/10.1093/jnci/dju044

[22] Dieperink KB, Mark K, Mikkelsen TB. Marital rehabilitation after prostate cancer - a matter of intimacy. International Journal of Urological Nursing. 2016; 10(1): 21-29. https ://doi .org/10.111 $1 /$ ijun. 12091

[23] Vermeer WM, Bakker RM, Kenter GG, et al. Sexual issues among cervical cancer survivors: how can we help women seek help? Psychooncology. 2015; 24(4): 458-64. PMid: 25858440. https : //doi.org/10.1002/pon. 3663

[24] Cullen K, Fergus K, Fitch M, et al. From "sex toy" to intrusive imposition: a qualitative examination of women's experiences with vaginal dilator use following treatment for gynecological cancer. $\mathbf{J}$ Sex Med. 2012; 9(4): 1162-73. PMid: 22304701. https ://doi.or $\mathrm{g} / 10.1111 / \mathrm{j} .1743-6109.2011 .02639 . \mathrm{x}$

[25] Bakker RM, Ter Kuile MM, Vermeer WM, et al. Sexual rehabilitation after pelvic radiotherapy and vaginal dilator use: consensus using the Delphi method. Int J Gynecol Cancer. 2014; 24(8): 1499506. PMid: 25248115.https://doi.org/10.1097/IGC. 000000 0000000253

[26] Krueger R. Focus Groups, A Practical Guide for Applied Research. Thousand Oaks: Sage Publications; 1994. 